\title{
CRISES DE APNÉIA COM INICIO PERINATAL NO LACTENTE
}

\author{
CAROLINA A, RODRIGUES FUNAYAMA - RICHARDO A. GALLINA \\ MARIA VALERIANA L. MOURA-RIBEIRO
}

\begin{abstract}
RESUMO - Foi estudado um caso de crises de apnéia em lactente e são discutidos aspectos clinicos, laboratoriais, radiológicos e achados de necrópsia. Uma característica narcante do quadro clínico foi a falta de resposta a várias terapèuticas utilizadas.
\end{abstract}

\section{Apneic spells in lactent, since perinatal period.}

SUMMARY - A case of neonatal apnea is reported. Clinical, laboratorial, radiological and pathological findings axe discussed. The failure of response to therapeutic procedures is suggestive of different cause than anoxia.

A apnéia indica ausência de movimentos respiratorios e, na criança em sono ou em vigilia pode ter duração de 5 a 10 segundos. Quando se alterna com a respiração normal, a condiçăo é conceituada como respiraçăo periódica 1. Entretanto, a constatação de pausa mais prolongada, superior a 20 segundos, é conhecida como apnéia simples, constituindo problema dos mais preocupantes em recém-nascidos (RN) prétermo 6. Aproximadamente 40 a $50 \%$ dos nrematuros, no periodo neonatal, apresentam respiração periódica, havendo correlação evidente con o grau de prematuridade 2,6 . Convém ter em mente, contudo, que a metade dos RN com respiração periódica pode apresentar apnéia em alguma ocasião. Apesar dos estudos dirigidos à fisiopatologia da apnéia no período neonatal, não está precisamente estabelecido, o defeito ou conjunto de elementos especificamente envolvidos 3,4 . Pode-se manifestar em RN, sem que a afeç̧ão básica seja identificada, sendo a causa indeterminada ou não associada à doença óbvia. Pode ocorrer secundariamente a entidades metabólicas (hipoglicemia, hipocalcemia), persistência do canal arterial, infecçóes neonatais (pneumonia, septicemia, meningite bacteriana), hemorragia intracraniana, sindrome do desconforto respiratório; pode estar associada a manifestações epilépticas, a depressão respiratória decorrente da administração de drogas às mães, no transcorrer do trabalho de parto, como, também, ser desencadeada por alimentação administrada através de sonda nasogásírica ou por acúmulo de secreçōes brônquicas 4,5 .

O objetivo da presente comunicação está ligado ao fato de o paciente ter apresentado apnéias desde o período perinatal e no transcorrer do primeiro ano de vida, com manifestação clínica de perda fôlego e/ou apnéias. A procura exaustiva do fator desencadeante durante o tempo total de internação visava esclarecimentos da fisiopatologia e tratamento.

Departamento de Neuropsiquiatria e Psicoloģia Médica da Faculdade de Medicina de Ribeirão Preto, Universidade de São Paulo (FMRP-USP). 


\section{OBSERVAC̄ĀO}

MAM, RN nascido no Hospital das Clínicas da FMRP-USP no dia 7 de junho de 1981, de māe com 21 anos de idade, cuja gestaçāo de 39 semanas teve resoluçãc por parto cesareano, sob anestesia geral, em tempo hábil, apesar da rotura uterina. O RN apresentou anóxia neonatal grave com indice de Apgar 1, no primeiro minuto, e 7 no oitavo minuto. Em função das condições vitais desfavoráveis, o RN não foi pesado nem medido ao nascimento. A māe refêt duas gestaçōes normais anteriores, resultando em partos normais. A crise de apnéia foi tvidenciada, pela primeira vez, aos 30 minutos de vida e, posteriormente, ocorreram crisos diárias, variando de 1 a 6 por dia. Raramente ficava um dia sem apresentar apnéias, quo eram de intensidade e duração variáveis: por vezes curtas, revertendo espontaneamente ou com a simples estimulação do paciente; outras vezes eram prolongadas e graves, acompanhadas de parada cardíaca, necessitando de cuidadosa assistência com oxigenacāo e massagem para sua reversão e normalizacão. Nos intervalos das apnéias a criança se mantinha bem, alimentando-se e dormindo normalmente. O desenvolvimento neuropsicomotor e pondero-estatural, avaliados semanalmente, demonstrou progressāo adequada com a idade cronológica. vários eventos puderam ser correlacionados ao aparecimento das apnéias diurnas, sendo os mais evidentes o choro, estimulos dolorosos e relacionados à administraçāo de medicamentos por via parenteral, exercicios e outros. Entretanto, algumas crises ocorreram espontaneamente, sem fator desencadeante registrável, e nunca foi evidenciada apné:a durante o sono. Os medicamentos empregados como estimulantes do centro respiratório, anticolinérgicos, benzodiazepinicos ou, por fim, anticonvulsivantes, não foram eficazes no controle das apnéias, sempre mantendo a mesma freqüência diária das crises, com ou sem medicaçāo. O eletrencefalograma, realizado no $18^{\circ}$ dia de vida, evidenciou ritmo lento difuso; um segundo cxame realizado no $30 \%$ dia, foi considerado normal; o terceiro exame, aos dois meses de idade, evidenciou pouca organizaçāo dos padrões fisiológicos do sono; exame realizado durante uma crise de apnéia evidenciou depressāo progressiva e global da atividade elétrica cerebral com posterior normalização do tracado. Os estudos radiológicos do crânio e coluni foram normais; o ultrassom de crânio, com um mês de vida, revelou áreas de menor ecogenicidade em gânglios da base. A tomografia computadorizada do crânio (CT), realizada com um mês de idade. revelou provável hemiatrofia cerebral esquerda; com dois meses de idade, novo CT foi sugestivo de hemorragia parietal direita; com 9 meses de idade, o exame evidenciou pequena area hipodensa fronto-temporal esquerda e dilatação da fissura silviana. Os testes de triagem para erros inatos do metabolismo foram negativos para os reguintes metabólitos: fenilalanina, cetoácidos, mucopolissacárides, porfirinas e grupos sulfidrila. Durante a permanência no berçário e, nos meses subseqüentes na enfermaria de Neurologia Infantil, apresentou 7 episódios de pneumonia, a maioria relacionados à aspiração do leite subsequ̇enté às apnéias ocorridas durante a alimentaçāo. Com 12 meses de idade, durante episódio de pneumonia, apresentou quadro de insuficiência cardíaca congestiva, de etiologia não esclarecida, com evolução desfavorável, levando o paciente ao óbito.

Necrópsia 343/82 - No exame necroscópico foram encontradas as seguintes alteraçôes patológicas: trombose da veia cava inferior, desencadeada por catéter de infusāo parenteral, que ocasionou insuficiência renal aguda e levou ao óbito; cardiomegalia global por cardiopatia anóxica crônica, com microinfartos e miocitólise; hiperplasia acentuada das lihotas de Langerhans do pâncreas (hiperpolinésia) semelhante à verificada em filhos de mães diabéticas (Fig. 1); cortical das supra-renais, tireóide e hipófise, sem alteraçōes. $O$ encéfalo (830g) apresentava sinais de hipertensāo intracraniana terminal, com giros achatacios e sulcos apagados. Ao corte, verificou-se presença de pequenas hemorragias laminares na linha divisória da substância branca com o manto cortical. Um cisto com liqüido citrino (hemorragia reabsorvida) ocupava o local da cabeça do núcleo caudado esquerdo. Nos pulmōes foi encontrada fibrose intersticial focal nas bases (sequela de aspiração de alimentos). Não foram encontradas anomalias nos presso-receptores carotídeos, no bulbo, hipotálamo e áreas corticais fronto-orbitárias.

\section{COMENTARIOS}

$\mathrm{Na}$ análise do presente caso, chama a atenção a precocidade do aparecimento das crises de apnéia, com apresentação clínica semelhante às crises de perda de fôleg( , por haver fator facilitador como o choro, por exemplo. Por outro lado, a persisiência das apnéias, sem melhora durante todo o primeiro ano de vida, sugere outra stiologia, que não a anóxia. Outro fato que chama a atenção è a faltá de 

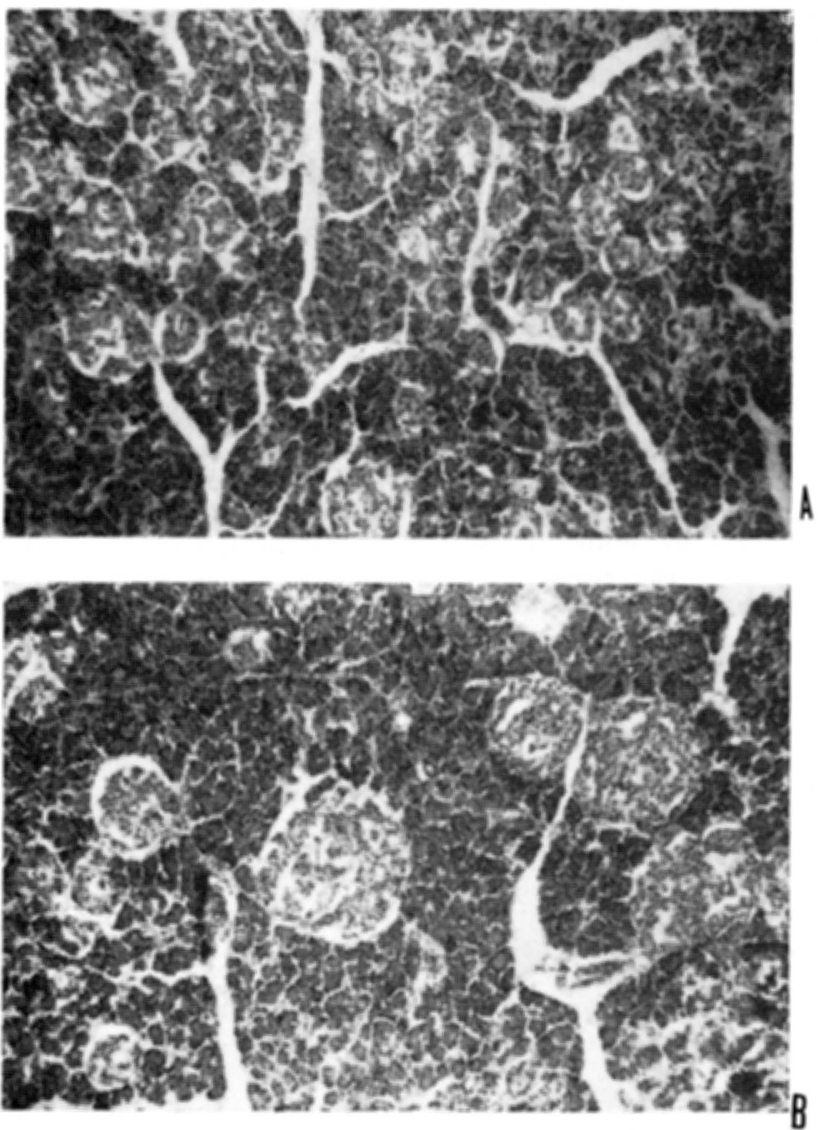

Fig. 1 - Caso MAM. Cortes histológicos de pâncreas (HE). Em A, hiperplasia das ilhotas de Langherans (×32); em $B(\times 80)$ e $C$ $(\times 180)$ observa-se associação dia hiperplasia com a hipertrofia.

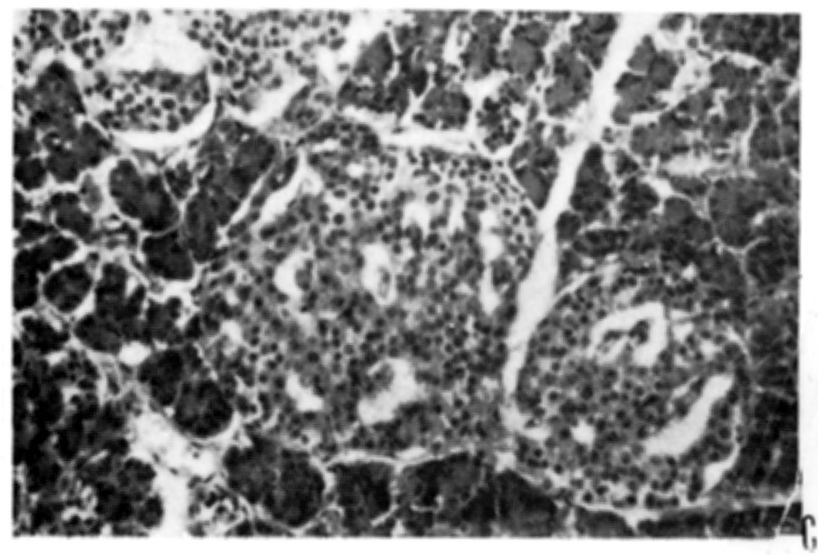


resposta aos medicamentos utilizados. Apesar da exaustiva investigação laboratorial no período de internação, não se conseguiu detectar alterações que explicassem o referido quadro clínico.

As lesões cardiacas e encefálicas, encontradas no exame anátomo-patológico, podem ser secundárias à hipóxia causada pelas crises de apnéia de longa duração. Estas crises poderiam ser desencadeadas pela hiperplasia das ilhotas de Langerhans que, ocasionando hipoglicemia periódica, levasse a síncopes hipoglicêmicas graves. Esta hipótese deve ser considerada se a monitorização dos níveis glicêmicos, efetuada durante as crises, mostrar estas variações. No presente caso, como a verificação de hiperpolinésia foi uma constatação necroscópica, as dosagens da glicemia foram as rotineiras e apresentaram valores normais. Contudo, observamos que as crises de apnéia nunca ocorreram enquanto o paciente recebia infusão venosa glicosada.

\section{REFFERENCIAS}

1. Booth CL, Morin VN, Waite WP, Thoman EB -- Periodic and non-periodic sleep apnta in premature and full-term infants. Develop Med Child Neurol 25:283, 1983.

2. Daily WJR, Klaus M, Meyer HBP - Apnea in premature infants: monitoring, incidence, heart rate changes and an effect of environmental temperature. Pediatrics 43:510, 1969.

3. Davi MJ, Sankaran K, Simons KJ, Simons ER, Seshia MM, Rigatto H - Physiologic changes induced by theophyline in the treatment of apnea in pre-term infants. J Pediatr 92:91, 1978.

4. Gabriel B, Albani $M$, Schulte FJ - Apneic spells and sleep states in pre-term infants Pediatrics $57: 142,1976$.

5. Kelly DH, Shannon DC - Periodic breathing in infants with near-miss sudden infant death syndrome. Pediatrics 63:355, 1979.

6. Rigatto H - Apnea. Pediat Clin N Amer 29:1105, 1982. 